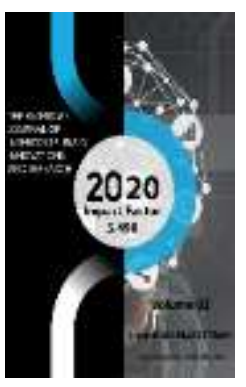

Journal Website: http://usajournalshub.c om/index,php/tajiir

Copyright: Original content from this work may be used under the terms of the creative commons attributes 4.0 licence.

\section{The Creation Of Electronic Educational Resources On The Subject "Ecological And Socio-Economic Problems Of Modern Energy"}

Razzokova Mohinur Baxodir Qizi

Master's Student In Renewable Energy And Environmental Physics Bukhara State University, Uzbekistan

\title{
ABSTRACT
}

This article focuses on the negative impact of the development of modern energy on the environment and the problems of reducing and preventing this impact. The role of the education system in solving such a global problem and the use of modern information technologies are discussed in article.

\section{KEYWORDS}

Energy technologies, atmosphere, Earth's hydrosphere, lithosphere pollution, ecological situation, environmental energy, Google service.

\section{INTRODUCTION}

Society was able to satisfy its needs almost without compromising harmony with nature for many years when people's energy needs were relatively small. However, the situation has changed significantly with the growing industrial burden of humanity, which relies heavily on advances in energy technology.
Changes in the chemical composition of the planet's atmosphere, pollution of the Earth's hydrosphere and lithosphere, the threat of the "greenhouse effect" on the Earth on a global scale, radioactive contamination of the region, the real threat of environmental disasters as a result of accidents at nuclear power plants, oil 
and gas production and oil refineries, complexes for the processing of chemical raw materials and radioactive waste - all this is not a complete list of phenomena that arise in the consequences of anti-environmental activities of energy facilities.

The modern world is faced with another serious problem that is relevant in addition to the difficult environmental situation at the same time. This is a question of ensuring the energy future of civilization.

The many regions of the world face severe energy supply challenges even today. On the whole, this has a very negative effect on the rates of their socio-economic development, leading to an increase in social, political, environmental and other contradictions in society. The limited reserves of mineral fuels, the continuous growth of the world's population, the steady growth of human needs for energy have highlighted the special urgency of the energy problem, putting it on a par with global problems such as the environmental safety of the modern world.

\section{MATERIALS AND METHODS}

The problem of correctly determining the socio-ecological prospects for the development of world energy has become a problem of the prospects for all mankind naturally. This task is to indicate one of the most important conditions for society to enter the path of sustainable development, which was discussed at the UN Conference on Environment and Development in Rio de Janeiro in particular (Brazil, June 1992 .).

A significant reduction in environmental energy conflicts can be achieved, provided that the energy needs of society are met and strict compliance with strict environmental protection requirements and savings in the use of natural energy resources at this stage. As a result of the analysis of possible ways to achieve this goal, the following can be singled out as priorities of the environmental strategy for the development of world energy in the early stages of overcoming the environmental and energy crisis:

- Improving the environmental performance of existing power systems and other energy and industrial facilities;

- Energy saving and rational use of natural resources;

- Improving the structure of theworld fuel and energy balance, mainly due to the increa se in the share of natural gas as an environmentally friendly fuel;

- Development and implementation of environmentally friendly technologies for the production and consumption of energy.

There is a figurative expression that we live in three eras of "economy, energy, ecology." ... At the same time, thinking about ecology as a science and image is attracting more and more attention of mankind.

The ecology is viewed as a science and educational discipline designed to study the relationship between organisms and the environment in all its diversity. In this case, the ecology means not only the inanimate world of nature, but also the influence of certain organisms or their communities on other organisms and communities.

The Modern ecology can be considered as a science that studies the interaction of organisms, including humans, with the 
environment, determining the degree and permissible limits of the impact of human society on the environment, as well as the possibilities for reducing or completely neutralizing this impact. From a strategic point of view, it is a way for people to survive and out of an ecological crisis that is global (or growing) on a global scale.

It is becoming more and more obvious that a person knows very little about the environment, about the mechanisms by which he lives, especially about the environment. Disclosure of these mechanisms (patterns) is one of the most important tasks of modern ecology.

Thus, the semantic, political, philosophical aspects of the term "ecology" acquired a social character. It is associated with the humanization of the natural and technical sciences and began to penetrate into almost all areas of knowledge, which is actively being introduced into the humanities. At the same time, ecology is viewed not only as an independent science, but also as a worldview designed to cover all sciences, technological processes and areas of human activity.

Thus, it is recognized that environmental training should be conducted in at least two directions through the study of special integrated courses.

Tht great attention is paid to respect for nature, cultural heritage and social preferences in addition to environmental education. The solution to this problem is also very problematic without serious general environmental education.

To improve the quality of education in this area, it is especially important to create e- learning resources aimed at studying the environmental, socio-economic problems of modern energy.

An electronic training resource is a training tool that helps to conduct lessons on the study of environmental, socio-economic problems of modern energy. This resource can be used to organize students' independent work in the study of theoretical materials, to organize practical and seminars, for leadership and selfgovernment. It can include many software tools, from illustrative materials and hyperlinked text documents to laboratory object emulators.

An e-learning resource should solve the following tasks:

- Equipping the educational process with educational, methodological, reference and other materials that improve the quality of education;

- Development of a tool for planning and organizing work to improve the educational and methodological base of an educational institution;

- Providing one hundred percent equipment of the educational process.

An electronic educational resource developed on a specific topic reflects the modern level of development of science, a logical and consistent presentation of educational material, the use of modern methods and techniques to accelerate the educational process, deep assimilation of educational material by students. It should be able to acquire skills to use in practice.

The modern trends in the development of society are directly related to the development of the information environment. The 21st 
century is the century of informatization, which covers all spheres of activity, including education. According to the Concept of informatization of the education system in Russia for the period up to 2020, informatization is a fundamental and most important task at the present stage. In addition, the modern information society is rapidly becoming mobile. This means that access to information and services is provided to users constantly, regardless of time and location.

Priority development of the information space of mobile education requires constant access to electronic educational resources and services, including at an educational institution, at home, on the road. This applies to all participants in the educational process: students and their legal representatives, teachers, leaders of the education system. The mobility of each participant in the educational process is becoming a prerequisite for success in the new information society. To provide such mobility, "cloud" technologies have appeared, the leaders among which are various Google services.

Google Services is a holistic system that anyone with a Google account can access. These web applications require only a browser and an Internet connection from the user.

The organization of mobile education through the use of Google services has several advantages:

- Access to information from any device connected to the Internet;

- Independence from the operating system and software on the local computer;
- The ability to use various applications for free;

- Joint work with data for reading or editing;

- Efficiency.

Among Google services, the most popular and contributing to the solution of basic educational tasks, one can single out "Google Docs", "Google Forms", "Google Drive", "Google Site". These services allow not only to develop and provide access to electronic educational resources, but also contribute to the organization of communication and collaboration of students, help the teacher to monitor and evaluate educational achievements, remotely manage learning and create an individual learning strategy in accordance with the needs of all participants in the educational process.

1. Using the service "Google Docs" in the educational process.

Today there are many office programs that allow you to create documents, such as the Microsoft Office suite of applications. However, they make it possible to use a readymade document or make changes to it only after obtaining individual access to it. These programs do not provide mobility of the process of creating and adjusting content.

Service "Google Docs" is a text editor that allows you to create and format documents, as well as work on them together with other users [8]. In the educational process, it will come in handy in the case when the teacher needs to draw up a congratulation on a holiday or an invitation to a parent meeting, write a short biography of all students in the class, write a mini-essay, draw up a reference outline, etc. This service does not require a special 
installation on a computer. To work with it, just go to "Google Docs" in the browser (service address -docs.google.com).

In addition to the capabilities of standard text editors, the Google Docs service has a number of additional advantages, the main of which are:

- Several users can work with a Google document at the same time, and they have access to them. They can make any edits to the document, edit it, leave their own comments about the content of the document, its design, communicate via chat in real time;

- The service supports a large number of popular formats (docx, pdf, odt, rtf, txt, html);

- When working with the service, the history of all edits ever made to the document is always saved, which is very important when correcting the content;

- It is possible to create and edit Google documents on iPhone, iPad and Android, which ensures the mobility of the process;

- If necessary, it is possible to work with the service in offline mode;

- It is possible to select access rights for each user or for individual groups. The service has three modes of collaboration on a document: editing, reading, commenting. Depending on what functions you assign to your students;

- Documents created in the service are automatically saved on Google Drive and can be viewed from any computer or mobile device (you just need to know the password to log into your account and have access to the Internet).
Google Docs is simple enough to work with. It has a conceptual interface and reference information with instructions for creating text documents. The service offers several steps in working with a document: creating a document; alteration; invitation of co-authors.

All documents presented in this service can be displayed on the page as a list or grid. In addition, for a faster search for the required material, all documents can be sorted by viewing date, by date of changes, by name.

The use of the Google Docs service in the educational process is not limited only to the collaboration of teachers and students. This resource can be used for joint methodological work of teachers within one or several educational institutions, for organizing joint thematic activities of parents, students and teachers, as well as for carrying out project and educational research activities within the framework of associations of interests or extracurricular activities.

2. Using the service "Google Forms" in the educational process

Google Forms is a feedback tool. With the help of the form, you can conduct various polls, quizzes, create questionnaires, tests. To do this, the user sets up a questionnaire with the required fields, sends a link to it to the participants and gets access to statistics based on the responses received. Forms can be designed to your liking, supplemented with images and videos. When you create a form, a Google spreadsheet is automatically created, which automatically accumulates the results of filling out the form. The table provides convenient options for storing and processing the collected data. 
The Google Forms allows you to create the following types of questions:

- The short text (the respondent is asked to enter a short answer);

- The long text (the respondent enters a detailed answer);

- One of many answer (the respondent must choose one answer from several);

- Several of the many (the respondent can choose several answers);

- Drop-down list (the respondent selects one option from the drop-down menu);

- Scale (the respondent should rate using a numerical scale, for example, from o to 10);

- Grid (the respondent selects specific points in a grid of columns and rows).

The main advantages of using the Google Forms service are:

- Ease of use, the interface is convenient and understandable, the form does not need to be downloaded, sent to your respondents and received from them by mail the completed version;

- Accessibility - the form is stored in the cloud and will remain accessible from any device, if there is a link;

- Individual design - the ability to create your own design for the form, choose a template from a large number of available ones or upload your own;

- Mobility - "Google Forms" is adapted for mobile devices. You can create, view, edit and send forms from your phone and tablet using a lightweight mobile with full functionality.

- Comprehensibility - "Google Forms" collects and professionally draws up statistics on responses, you do not need to additionally process the received data, you can immediately start analyzing the results.

\section{CONCLUSION}

In conclusion, we can say that the current level of scientific progress and existing developing technologies provide the basis for optimistic forecasts: humanity is able to overcome the risk of crisis, the risk of depletion of energy resources and environmental problems caused by intensive production. There are real opportunities to switch to alternative energy sources (inexhaustible and environmentally friendly).

Modern methods of obtaining energy from these positions can be considered as a kind of transitional. The question is how long this transition period lasts and what are the options for its reduction ...

The use of Google services plays an important role in the training of environmental and energy specialists, providing them with continuous professional development..

The using of the Google Docs service in the educational process is not limited only with the joint work of teachers and students. It can be used for joint methodological work of teachers, for organizing joint activities of parents, students and teachers, for carrying out project and educational research activities.

Google Forms is a feedback tool. With its help, it is possible to organize effective work to control the educational activities of students, to identify the educational needs of all participants in the educational process.

The Google Drive service is organically included in the educational process, making it more dynamic and effective. The service allows 
organizing joint activities of teachers and students, makes it possible to work together remotely from each other, create a library of didactic materials and Olympiad tasks, methodological piggy banks to improve the efficiency of the educational process.

The service "Google Sites" allows any participant in the educational process to access the necessary information at a convenient time, will ensure the mobility of the educational process.

\section{REFERENCES}

1. Handbook of power engineering A.I. Panfilov, V.I. Engovatov 2006

2. D.P. Eltzarov "Thermal Power Plants of Power Plants". - M 1982

3. T.A. Akhimova, A.P. Kuzmin "ecology. Nature - man - technology". - M. 1982, 343 p.

4. N.A. Voronkov, general, social, applied ecology: a textbook for students - $M$.: Agor, 2003

5. Kosichkina, AS Features of the design and development of electronic educational resources for an educational organization / AS Kosichkina. - Text: direct // Young scientist. - 2016. - No. 27 (131). - S. 23-27. URL: https://moluch.ru/archive/131/36593/ (date of access: 23.12.2020).

6. Interactive worksheets [Electronic resource] / Website. - Access mode: https://sites.google.com/site/intelworksh eets/

7. Training "Cloud technologies for data storage and processing, organization of interaction" [Electronic resource] / Website. - Access mode: http://manualgoogledrive.blogspot.ru/
8. About Google Drive [Electronic resource]/ Website. -Access mode: http://www.youtube.com/watch?v=jUShR TPsKrY

9. Atoeva M.F. Frequency of teaching physics. Postgraduate student and applicant. - Moscow, 2010. - No. 6. - S. 4143.

10. M.F. Atoyeva. Interdisciplinary relations in physics course at specialized secondary education. The Way of Science. Volgograd, 2016. - №9 (31). - P.22-24.

11. M.F. Atoyeva. The significance of periodicity at teaching physics. The Way of Science. - Volgograd, 2016. - № 10 (32). P.62-64.

12. Atoeva M.F. The effectiveness of teaching electrodynamics based on the technology of periodicity. The Way of Science. Volgograd, 2016. - No. 10 (32). - P.65-66.

13. M.F. Atoyeva. Use of Periodicity in Teaching Physics. Eastern European Scientific Journal. - Düsseldorf-Germany, 2017. № 4. -P. 35-39.

14. M.F. Atoyeva. Didactic foundations of inter-media relations in the training of university students. International Scientific Journal. Theoretical \& Applied Science. p-ISSN: 2308-4944 (print) e-ISSN: 2409-0085 (online). Year: 2020 Issue: 06 Volume: 86, P. 124.

15. M.F. Atoyeva, R. Safarova. Pedagogical integration as a means of forming professionally important qualities among students of a medical university. Academicia. ISSN: 2249-7137 Vol. 10, Issue 8, August 2020. Impact Factor: SJIF $2020=$ 7.13 ACADEMICIA: An International Multidisciplinary Research Journal https://saarj.comэ. 
16. M.F. Atoyeva. Pedagogical Tests As An Element Of Types of Pedagogical Technologies. The American Journal of Applied Sciences, 2(09), (TAJAS) SJIF5.276 DOI-10.37547/tajas Volume 2 Issue 9, 19.09.2020. ISSN 2689-09. 92 The USA Journals, USA www.usajournalshub.com/inde x.php/tajas 164-169. Имп.5.2.

17. Farkhodovna, A. M. (2020). The problems of preparing students for the use of school physical experiment in the context of specialized education at secondary schools. European Journal of Research and Reflection in Educational Sciences, 8 (9), 164-167.

18. Saidov S.O., Fayzieva Kh. A., Yuldosheva N. B. Atoyeva M.F. The Elements Of Organization Of The Educational Process On The Basis Of New Pedagogical Technologies. The American Journal of Applied Sciences, 2(09),(TAJAS) SJIF-5.276 DOI-10.37547/tajas Volume 2 Issue 9, 19.09.2020. ISSN 2689-09.92 The USA Journals, USA www.usajournalshub.com/index.php/taja s 164- 169. Имп.5.2. 